\title{
Book Review: Modern Epidemics, From Spanish Flu to COVID-19 by Salvador Macip Maresma
}

\author{
Paola A. Vargas ${ }^{1,2 *}$, Lucia Elena Alvarado-Arnez ${ }^{3}$ and Natalia Montellano Duran ${ }^{1}$ \\ ${ }^{1}$ Biotecnología, Universidad Católica Boliviana San Pablo, Santa Cruz, Bolivia, ${ }^{2}$ Instituto de Investigaciones de Enfermedades \\ Tropicales IIET, Universidad Nacional de Salta UNSA, Salta, Argentina, ${ }^{3}$ Coordinación Nacional de Investigación, Universidad \\ Privada Franz Tamayo (Unifranz), La Paz, Bolivia
}

Keywords: epidemic, pandemic, virus, microbes, disease, treatments, vaccines, book review

\section{A Book Review on}

Modern Epidemics, From Spanish Flu to COVID-19

by Salvador Macip Maresma

There is an extended idea that microbes have a negative connotation. However, scientific findings have shown that while multiple bacteria are indeed pathogenic, causing infection and compromising health, there is a larger group of symbiotes that result beneficial to us. The smallest known units of life also form an important part of our internal and external ecosystem, playing relevant roles in maintaining homeostasis.

As a specialist in the biology of infectious diseases, Salvador Macip presents the fascinating world of microorganisms in a simple and understandable manner (Part I of the book). Even though microbes populated the Earth before humanity, we have just recently become aware of their significance. In an incredibly attractive way, the author manages to synthesize his extensive knowledge in this area.

Macip walks us through the history of the epidemics: how long it took us to deal with the diseases driven by microbes and illustrating that epidemics have always been a part of human history, ever since the Roman Empire up to the current COVID-19 pandemic, molding history during its course. Therefore, it is mandatory to strengthen health policies: continue research for potential treatments and vaccine candidates for disease surveillance and control.

When humanity depended only on its immune system to fight infections, the life expectancy was around 25-30 years and with elevated infant mortality rates, thanks to the development of medical and biological sciences; in the 20th century, life expectancy in developed countries rose to 80 years. The book overviews these changes, and how they improved life expectancy, from urban city planning development, disinfection methods to antimicrobials, and mass population vaccination.

Biological weapons pose a threat to humankind, and in the book, the author describes how many local or foreign plague epidemics have been responsible for defeating armies in multiple wars throughout history. Conversely, the book presents a scenario where the knowledge of viruses and microorganisms must be responsibly managed.

To complete the first part, the author brings focus on diseases such as meningitis, cholera, West Nile virus, Ebola, and Marburg as causal agents of sporadic outbreaks in determined places. These emergent diseases affect millions of people around the world, and the author remarks how they remain important pathogens to focus on.

In the second part of the book, Macip emphasizes on actual major modern epidemics like influenza, AIDS, TB, and malaria. Influenza virus causes flu and is the most prevalent viral disease, causing thousands of deaths every year around the world. Despite its low fatality rate, most of the 
victims include vulnerable groups such as children and the elderly. Also, the author refers to acquired immunodeficiency syndrome, AIDS, and how it could be considered the worst plague in human records with hundreds of millions of people currently affected around the world. Finally, tuberculosis is featured as a disease that has been known since the XIX century but now is associated with widespread multidrug resistance (MDR and XDR).

Along the book, several similarities are found between past epidemics and the COVID-19 pandemic, such as the lack of diagnostic precision and ineffective control. This in turn makes it difficult to contain these epidemics, becoming them into pandemics with a high death toll despite the low mortality rate, due primarily to a large number of infections. As historical data shows, pandemics develop in regular time intervals of approximately $10-70$ years, so we must be prepared for the next one, setting a constant challenge for scientists and the society itself.

This journey through the history of our coexistence with microorganisms, and how they can trigger a major global health crisis, makes us aware of the imperative need for research and technological development. The data presented by Macip leaves in evidence the need to implement preventive strategies, to ensure appropriate coordination between governments and its institutions, and to strengthen health systems around the world. The past and recent experiences will serve to define a collaborative taskforce to face the potential biological crisis to come.

\section{AUTHOR CONTRIBUTIONS}

All authors listed have made a substantial, direct, and intellectual contribution to the work and approved it for publication.

Conflict of Interest: The authors declare that the research was conducted in the absence of any commercial or financial relationships that could be construed as a potential conflict of interest.

Copyright (c) 2021 Vargas, Alvarado-Arnez and Montellano Duran. This is an openaccess article distributed under the terms of the Creative Commons Attribution License (CC BY). The use, distribution or reproduction in other forums is permitted, provided the original author(s) and the copyright owner(s) are credited and that the original publication in this journal is cited, in accordance with accepted academic practice. No use, distribution or reproduction is permitted which does not comply with these terms. 